\title{
School based scoliosis screening: an analysis of socio-demographics, compliance, efficacy and a proposed role for physical therapists in a state mandated program
}

\author{
Arsenio Paez*1,2, Denise Lotufo ${ }^{1}$ and Mary Ann Wilmarth ${ }^{1}$
}

\author{
Address: ${ }^{1}$ Northeastern University, Bouve Institute of Health Professions, School for Professional and Continuing Studies, Boston, MA, USA and \\ 263 Reynolds Drive, Fairfield, CT 06824, USA \\ Email: Arsenio Paez* - artiep@aol.com \\ * Corresponding author
}

from 4th International Conference on Conservative Management of Spinal Deformities

Boston, MA, USA. 13-16 May 2007

Published: 12 October 2007

Scoliosis 2007, 2(Suppl I):S43 doi:I0.II86/I748-7|6I-2-SI-S43

This abstract is available from: http://www.scoliosisjournal.com/content/2/SI/S43

(c) 2007 Paez et al; licensee BioMed Central Ltd.

\section{Objective}

School scoliosis screening programs are mandated across the United States, but their efficacy remains controversial [1-3]. This study investigates data from the Massachusetts program, examining its efficacy and follow up attained after a positive screen.

\section{Study design}

This retrospective cohort study analyzes data for 272,337 students in grades 5-9 from 1989 to 2005 in Massachusetts. Regression and data analyses determined the incidence of scoliosis over the life of the program, its predictive value, specificity and the rate of follow up attained after screening.

\section{Results}

The incidence of scoliosis was $0.55 \%$, or 1489 students from 1989 to 2005. The program's positive predictive value was low, at $.50 \%$, or 1 confirmed diagnosis per 200 students screened. Children in lower socioeconomic strata were more likely to be identified for possible scoliosis than other students. Girls were identified and diagnosed with scoliosis increasingly over time. Compared to other programs, fewer students per thousand were positively screened for scoliosis in MA, though follow up evaluation was incomplete for $72 \%$ of those students.

\section{Conclusion}

Sociodemographic factors may influence the identification of students at risk. Methodological issues significantly influence the program's efficacy and ability to meet its goals, including bringing those identified to follow up care.

\section{References}

I. Bunnell WP: Selective screening for scoliosis. Clinical Orthopaedics \& Related Research 2005, 434:40-45.

2. Bunge EM, de Koning H]: Selective screening for scoliosis. Clinical Orthopaedics \& Related Research 2006, 445:277-278.

3. Bunge EM, Juttmann RE, de Koning HJ: Steering Committee of the NESCIO Group. Screening for scoliosis: do we have indications for effectiveness? Journal of Medical Screening 2006, 13:29-33. 